\title{
O que importa para você?
}

\section{RDSL 2019}

REDE 20 ÓR Sñ̄O-UIZ 


\section{EP \\ Experiência do Paciente}

\begin{tabular}{c|c|c|c} 
S & CC & SA & DC \\
Satisfação & Cuidado & Segurança & Desfecho \\
do Paciente & Centrado & & Assistencial \\
e do Colaborador & no Paciente & &
\end{tabular}




\section{“O que importa para você?"}

\section{0}

O movimento O que importa para você? teve início nos Estados Unidos. CEO do instituto norte-americano Healthcare Improvement na época, Maureen Bisognano foi uma das pessoas que desafiaram os profissionais de saúde a terem conversas mais próximas com os pacientes e familiares. A partir desse estímulo, a preocupação assistencial começou a mudar de "qual é o problema?" para "o que importa para você?".

Na Escócia, o movimento também se iniciou em meados de 2010. Influenciado por esse contexto de cuidado, dois enfermeiros escoceses, Jennifer Rodgers e Shaun Maher, desenvolveram maneiras para descobrir o que importava para os pacientes. O trabalho de Jennifer era em uma unidade pediátrica, onde ela desenvolveu um processo que permitia que todas as crianças internadas criassem cartazes mostrando o que importava para eles. Assim, cada paciente deixava esse cartaz no seu leito para que todos os profissionais de saúde pudessem entendê-los.
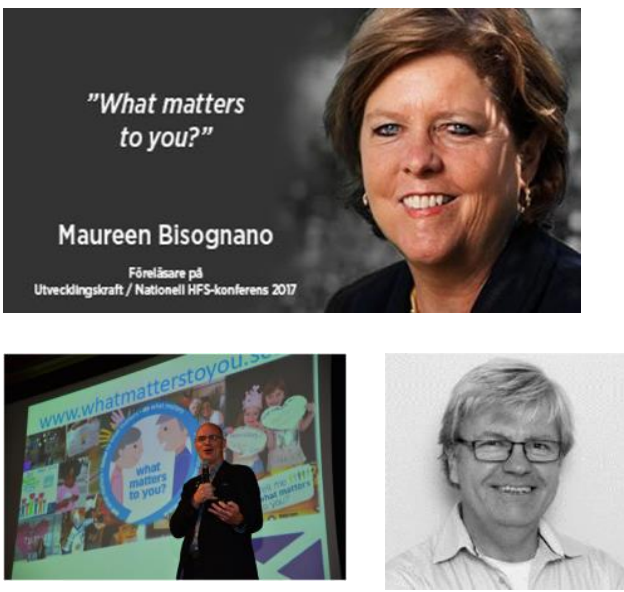

2012

O primeiro artigo sobre o assunto foi abordado pelo Dr. Michael Barry na publicação científica voltada à Medicina "New England Journal of Medicine", com o tema Shared Decision Making - The Pinnacle of PatientCentered Care (Tomada de Decisão Compartilhada - O Auge do Cuidado Centrado no Paciente), trazendo a reflexão de que o fundamental é compreender o que é primeiramente importante para o paciente. A ideia discutida foi a de que os profissionais de saúde começassem a priorizar as necessidades e perspectivas dos pacientes e familiares para, então, direcionar e melhorar os atendimentos assistenciais.

\section{4}

Com base nas discussões sobre o movimento $O$ que importa para você?, profissionais de saúde da Noruega lançaram um programa de longa permanência para idosos com o objetivo de promover, ainda mais, a saúde de cada um deles e apoiá-los a viver com suas preferências.

Foi, então, que o dia 06 de Junho foi instituído por Anders Verge, enfermeiro e chefe de um Departamento de Melhoria da Qualidade, como sendo data oficial da campanha $\mathrm{O}$ que importa para você?. Neste ano de 2014, aproximadamente 500 equipes, na Noruega, participaram do movimento.

\section{5}

Cerca de 1.500 equipes, na Noruega, aderiram à campanha, em diversas áreas, como em serviços comunitários e escolas. Contudo, faltava reforçar a ação para os hospitais.

Para impulsionar a cultura do cuidado centrado no paciente, uma conferência nacional em Glasgow, na Escócia, foi realizada e, também através de divulgações em redes sociais, o movimento 0 que importa para você? passou a se tornar reconhecido internacionalmente. Profissionais do mundo inteiro começaram a compartilhar suas experiências de conversas com seus pacientes, iniciadas a partir da importância do movimento.

\section{6}

Mais de 500 equipes, na Escócia, juntaram-se à Noruega.

Mais 13 países aderiram ao movimento, incluindo o Brasil.

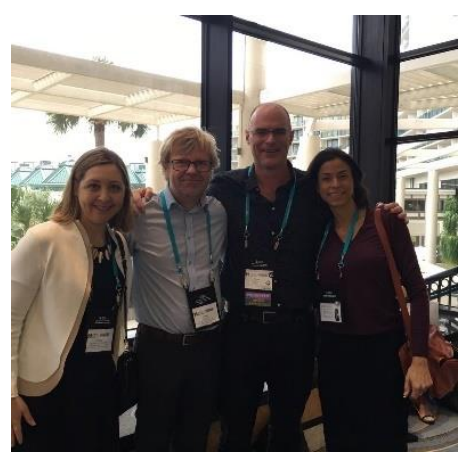

Fonte:http://www.acsc.org.br/oqueimportaparavoce/como-se-originou-2/ 


\section{Experiência do Colaborador - IHI}

A inspiração para o trabalho foi baseada na publicação do IHI Framework for Improving Joy in Work

$\square$ Alegria no trabalho - ou a falta dela - não só impactam no engajamento e a satisfação das pessoas, mas também na experiência do paciente e na qualidade do atendimento;

A publicação visa servir como um guia para que as organizações de cuidados de saúde se envolvam no processo participativo em que os liíderes perguntam aos colaboradores de todos os níveis "O que importa para você?" capacitando-os a entender as barreiras existentes no trabalho e co-criar estratégias significativas de alta alavancagem para abordar esses problemas. 


\section{Use improvement science to test approaches to} improving joy in work in your organization

3. Commit to a systems approach to making joy in work a shared responsibility at all levels of the organization

\section{Identify unique impediments to joy in work in the local context}

\section{Ask staff, "What matters to you?"}

Fígura: Four Steps for Leaders, IHI Framework for Improving Joy in Work 
1. Perguntamos "o que importa para você" para equipes de 14 hospitais em SP;

2. Palestras conceitual sobre experiência do paciente;

3. Voltamos a perguntar aos colaboradores "o que importa para você"

Respostas:

Classificação A e B

$\square$ 79\% Bem estar emocional;

$\square$ 13\% Qualidade de vida no trabalho;

$\square$ 9\% Bem estar emocional e Qualidade de Vida. 


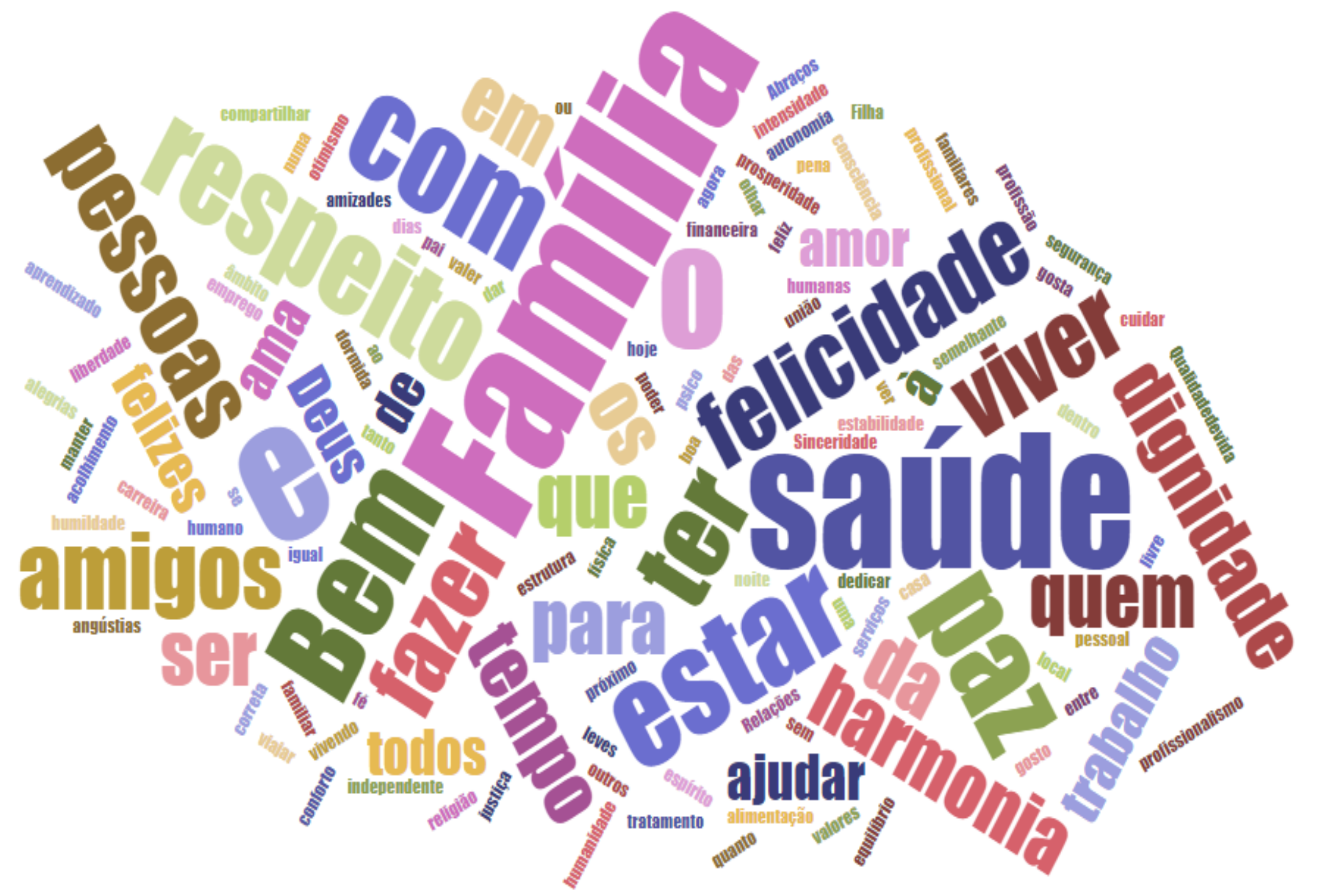


"Família, trabalho com dignidade, viver com intensidade, paz"
"Reduzir o sofrimento, valorizando as necessidades das pessoas no seu dia a dia"
"Trabalhar com qualidade de vida, acolhimento e gentileza, ter um olhar voltado as necessidades do outro, empatia"

Obter mais conhecimento com os profissionais da área da saúde, experiência, não só em relação à doença e o paciente, mas sim ao aspecto mais amplo do humano como ser biopsicossocial
"O respeito com que eu trato meus colaboradores, pois assim sei que eles tratarão com respeito nossos clientes"

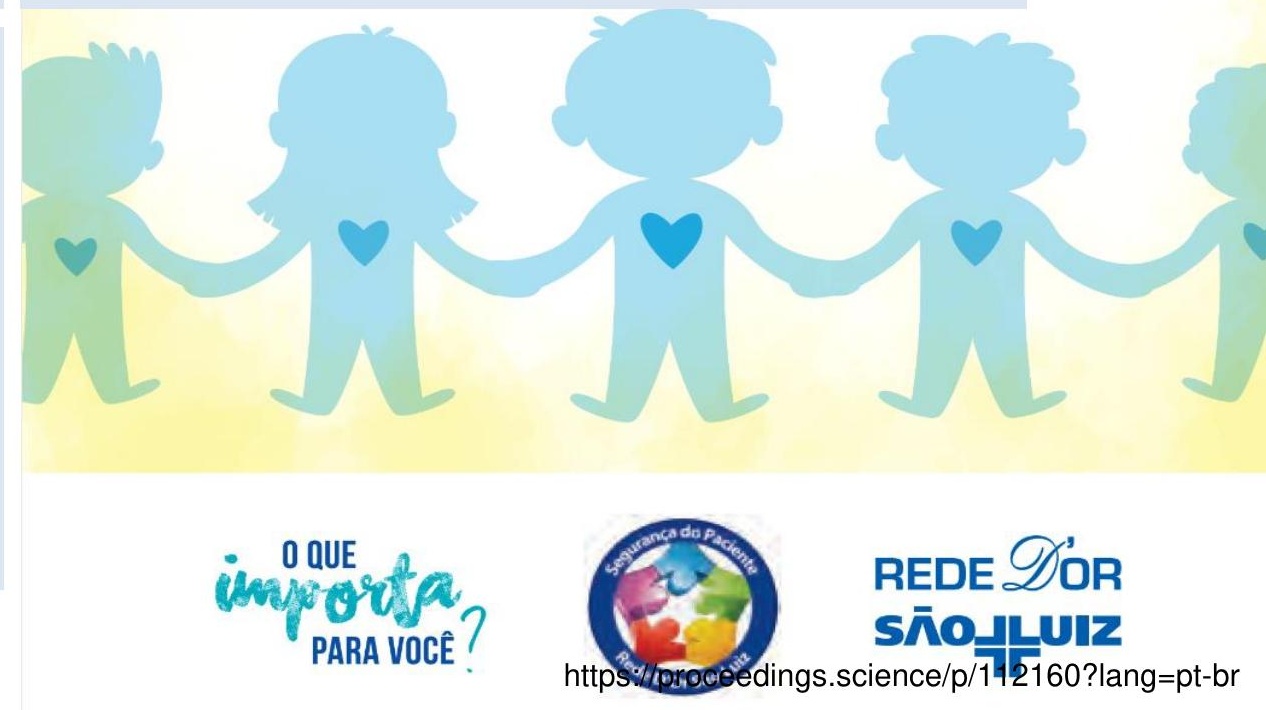


“Foi incrível e gratificante participar ativamente de uma ação como essa.

Percebi que devemos valorizar os pequenos momentos da vida e nos tornar mais sensíveis e humanos pra

que tenhamos a capacidade de entender as necessidades do outro."

"Enquanto nós almejamos grandes conquistas, as pessoas internadas desejam coisas muito simples como feijão, espumone, ovo cozido... O que faz a gente como pessoa refletir o que é importante para a vida"

“Experiência incrível! Que nos faz reestruturar o que realmente importa quando estamos bem e que como curtos segundos podem representar longas e até indeléveis lembranças em nossas vidas!"
"Foi maravilhoso. Por mim teria todo mês porque foi uma experiência única.

Consegui enxergar como é estar do lado do paciente e que pequenas ações fazem a diferença durante $o$ internamento"

"Por vezes sentimos que aquilo que fazemos não é senão uma gota de água no mar. Mas o mar seria menor se lhe faltasse uma gota"
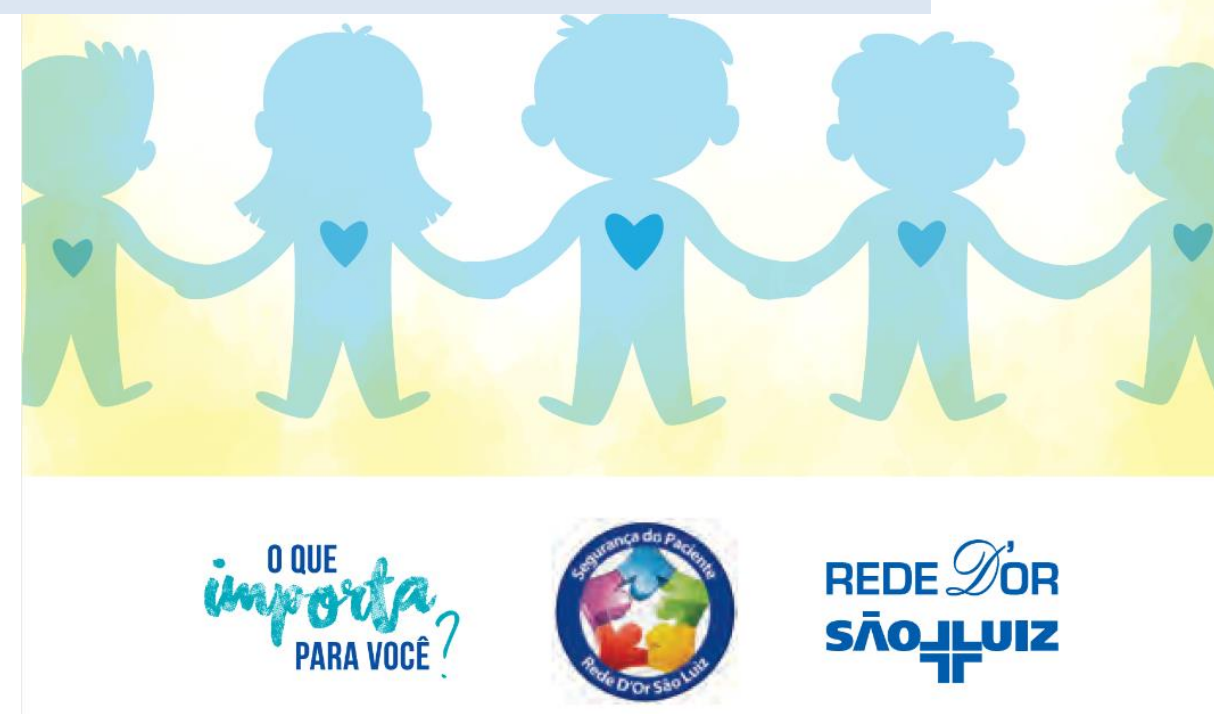


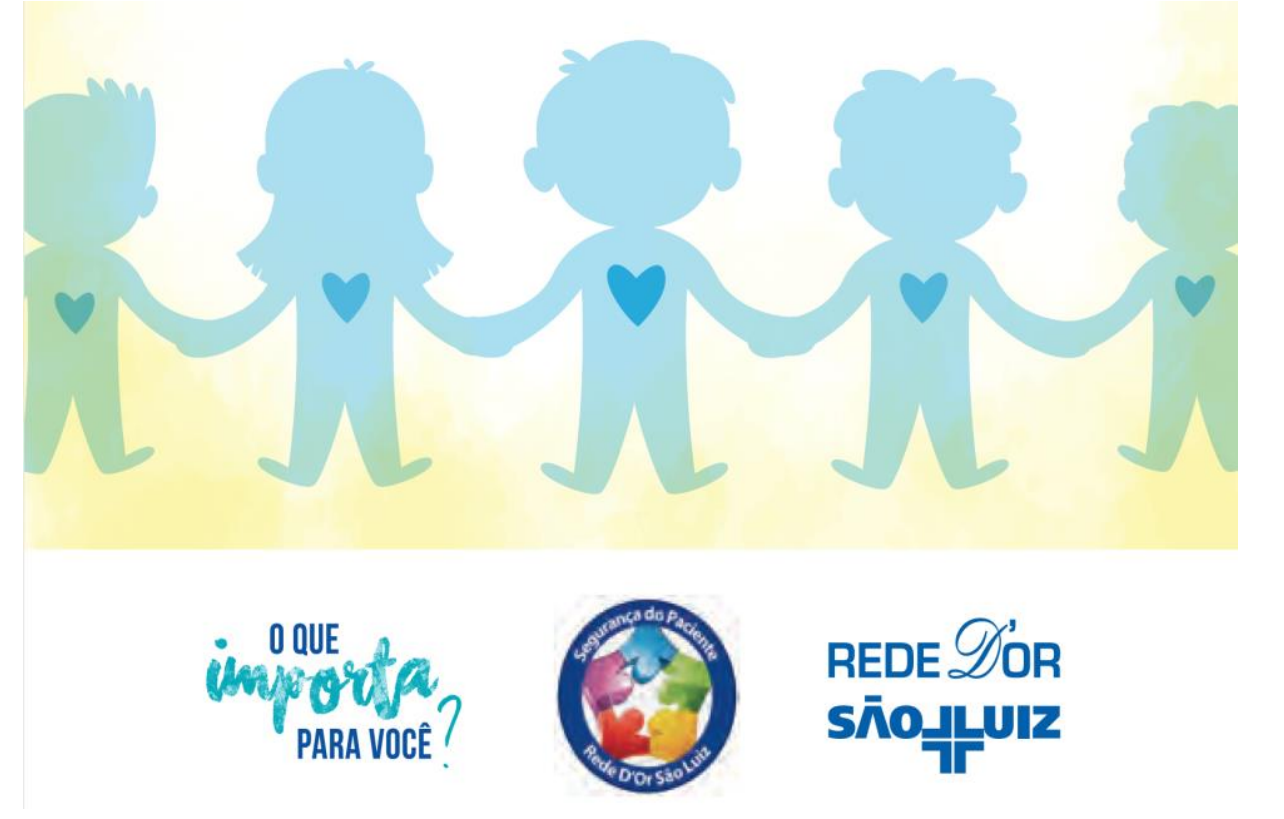

\section{OBRIGADA!}

Angela Zerbielli angela.zerbielli@rededor.com.br 